\title{
EaTable: the future of smart interaction cuisine for one-person household.
}

EaTable: o futuro da cozinha inteligente de interações para uma pessoa doméstica.
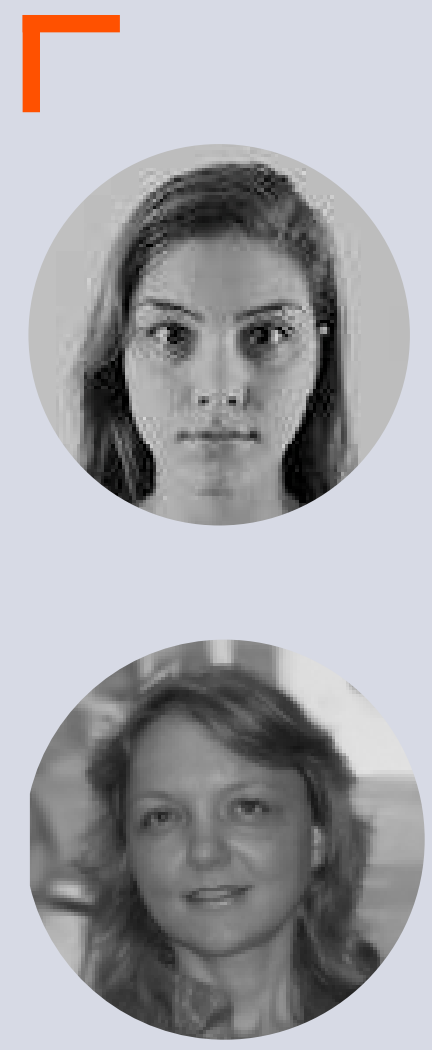

Eleny Carolien Hillenia Meiborg

Federal Technological University of Paraná DADIN - Department of Industrial Design e-mail: emeiborg@alunos.utfpr.edu.br

Rosamelia Parizotto Ribeiro, P.h.D

Federal Technological University of Paraná DADIN - Department of Industrial Design e-mail: rosamelia@utfpr.edu.br 


\section{Abstract}

This paper aims to present an investigation made on dietary behaviors of one-person households, starting from the premise on how to improve the life of elderly people who eat alone. Using the MediaLab Amsterdam Design Toolkit, in a conceptual design class, the concept for a smart kitchen apparatus was created, presented and further evaluated with The Emoji Tool.

\section{Keywords}

Smart Kitchen; One-Person Household; Dietary Behavior.

\section{Resumo}

Este artigo tem o objetivo de apresentar uma investigação sobre o comportamento das famílias unipessoais, partindo da premissa de como melhorar a vida dos idosos que comem sozinhos. Usando o MediaLab Amsterdam Design Toolkit, em uma classe de design conceitual, o conceito de um aparelho de cozinha inteligente foi criado, apresentado e avaliado com a ferramenta Emoji.

\section{Palavras-chave}

Casa de uma pessoa; Comportamento Dietético. 


\section{Introdução}

Through the course of multiple discussions inside the Conceptual Design class at the Federal Technological University of Paraná (UTFPR) the Design Method Toolkit, from MediaLAB Amsterdam (2017) was introduced with the intent to show students different tools of problem solving using teamwork as a methodology. The discipline assignment, was primarily to target elderly people that lived alone, who couldn't cook or prepare their own meal. With the toolkit, a plan was outlined by a group of students on how to improve the elderly cooking and eating experience using something other than a mobile application or mainly digital gadget. This imposition was assumed so that the user would be forced to interact with someone else, friend or unknown. However, after a primary research, the user was broadened, showing that the concept could help not only the elderly, but everyone who could afford living alone and was still missing out on an improved experience during their meals, as well as a healthy diet. Therefore, it was important to understand the variety of tools available to design the concept with an interaction that could increase the knowledge of healthier cooking and eating for a broader age range of people, taking the use of a device or gadget back into consideration. Consequently, a concept idea was proposed, and the analysis of its functionality was made by classmates and outside class students with The Emoji Tool (Ribeiro et al., 2016), generating data for its validation.

\section{The Design Method Toolkit (MediaLAB Amsterdam)}

The MediaLAB Amsterdam (2016) usually works on projects areas focused on citizen empowerment, promoting big impact on everyday life through digitization, which means, "The conversion of text, pictures, or sound into a digital form that can be processed by a computer." (OXFORD ENGLISH DICTIONARY, 2017).

The Toolkit methodology consist on the use of tool cards, divided into categories relating to the goals of the project. The tool cards are split into either Research, by gathering information and making sense of it, or Create, by trying to objectify something tangible such as prototype.

Associated with research and create, are five categories, demonstrating what the tool is about: Know the User - Explores the background of the project, the context, the situation, location, time and social/technical context; Define Goals and Intentions - Define the challenge's vision, objectives, 
scenarios, scopes and constraints; Frame Your Insights - Draw conclusions from the research and make lessons learned explicit; Ideation and Concepts - Generate ideas and Concepts, explore possibilities and ideas in a very broad sense; Create and Test - Ways to get from concepts to production, prototyping and testing (MEDIALAB AMSTERDAM, 2017).

A mind map (figure 1), of the tool cards research and create and their categories, was created as a starting point of the concept project, by identifying amongst the wide variety of tools which performed better regarding the user and the interaction desired. The selected tools were the WWWWWH, Persona, VIP Deconstruct, Empathy Map and VIP Design. In addition, because the concept was never intended to be prototyped nor tested, there is only a representation of the category Create and Test in figure 1.

Figure 1- Tool Cards Mind Map.

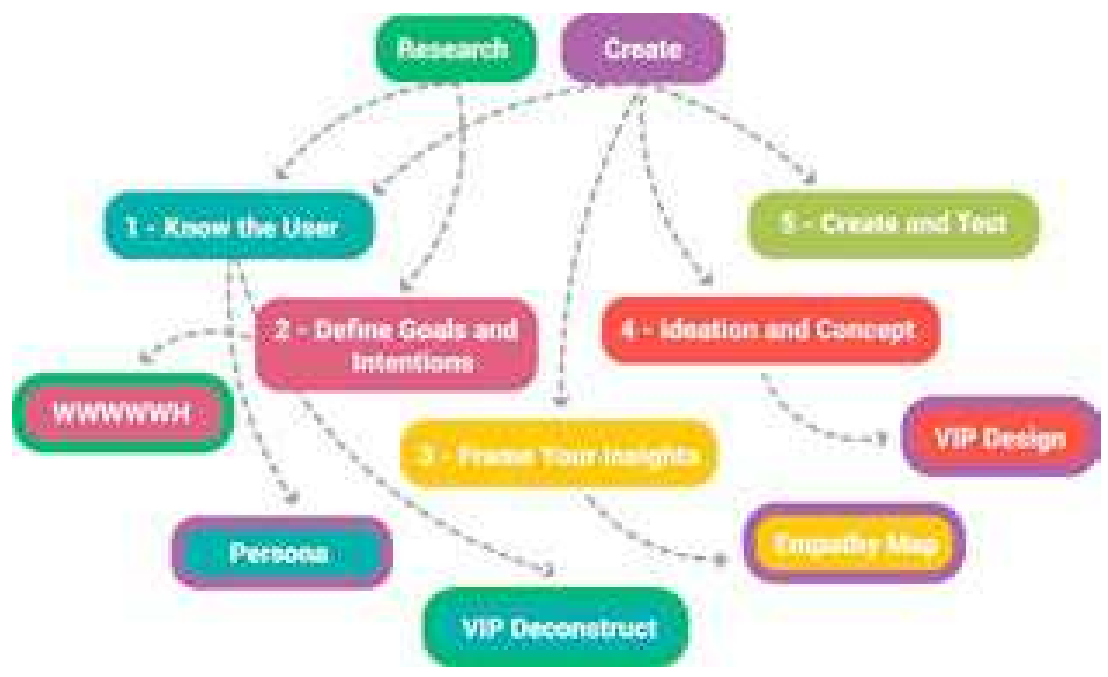

Source: Eatable - Authors, 2017.

\section{WWWWWH (Research + Define Intentions)}

To answer the first issue of every design project, the Toolkit suggests to start a project by knowing the user and define goals and intentions. The WWWWWH tool was select to determine the problem definition and the problem statement by answering the questions: Who is involved? What occurred? When did it happen? Where did it happen? Why did it occur? How did it happen? (MEDIALAB AMSTERDAM, 2017). 
The main motives, for people to start shifting from the previous model of living to the new trend of solo living, is the wealth generated by economic development and the social security provided by modern welfare states, these common conditions, according to Klinenberg (2012) are the reasons why the number of people living alone globally is skyrocketing, increasing around 80\% from 1996 to 2011. Consequently, the levels of one-person households tend to be substantially higher in developed countries than in developing countries (CHAMIE, 2017).

According to Chamie (2017) growing numbers are choosing to pay for their personal privacy, individualism and freedom to live as they wish, meaning that more people are able to afford living alone, which is also happening due to industrialization, urbanization, opportunities and multitude of services that now allow a lifestyle promotive to living on one's own, whereas in 1960 two-thirds of the world's population lived in rural area and today the majority of the world's population (55 percent) lives in urban centres.

The fact that more people started to live alone inevitably suggests that now more people eat alone, besides, the growing industrialization and modernization of lifestyles helped develop discussions that traditional, collective ways of eating such as commensality are being replaced by individual eating, including eating alone and individual choices of food (TAKEDA, 2016). However, these discussions of individualization of eating increases its attention to behaviors directed by individualism and consumerism and ignores the fact that these discourses are developed within social contexts (GERMOV, 1997). Somehow, it is the same social context in which food consumerism has greater influence on human behaviors and decision-making than the basic physiological functions of hunger and fullness on a diet (HERMAN et al., 2003). These behaviors will be explored on the next method, where there is an attempt to discuss the users' needs.

\section{Persona (Create + Know the User)}

This tool creates an archetypical character that is used to represent a group of possible users (MEDIALAB AMSTERDAM, 2017), which in this project will be represented by a male and female persona who live alone, characterizing their attitudes and behaviors towards eating and cooking.

Within the research for possible users what also became known to define the personas was that in spite of the rapid rise in one-person 
households, among young people, it became common a delaying of marriage and family building due to higher education, professional training, career aspirations, personal goals. Also, on top of lower marriage rates and smaller family sizes, growing numbers are choosing to remain childless (CHAMIE, 2017). Since all of these domains of everyday life have become privatized, in the sense that they have fallen into the private sphere of decision by becoming subject to individual and personal choices, one can assume that food choices and eating can't be ruled out (FISCHLER, 2011).

In a way, Fischler (1980; 1990) says that the rules and norms concerning food and eating began to dissolve as the social practices related to them changed. Individuals lost their sense of what, how and when they should eat.

Considering that meals are what regulates social life and individual behavior, both at a social and a biological level, by giving the fundamental dimensions of everyday nourishment (FISCHLER, 2011; RICHARDS, 1932).

Healthy habits are always a concern in societies, but bad habits can reveal more about the personas projected in this work, and because of such habits a research done in Japan by Tani et al. (2015) became so important. It showed that the associations between eating alone and the risks for obesity and poor dietary behavior in men and women, what can be very different among old adults. The results showed that men demonstrated to be more susceptible to obesity and poor dietary behavior among those living alone, just the contrary of women who ate alone, the risks were higher in among those who lived with others. Something to be explained by Pliner et al. (2009) with two social mechanisms that modulates food intake; by Modeling, when eating in the presence of someone eating a lot or too few, it can increase or decrease intake, respectively; and through Social Norm, that is when in company, people tend to adjust their intake and behave 'appropriately', conforming to their commensals' behavior, but when in private, individuals stop being influenced by the need to gain approval and will eat as much as desired.

While is important to show that there is a gender difference, they exist more because of differences in cooking skills and nutritional knowledge (HUGHES et al., 2004; BAKER et al., 2003). The lack of cooking skills may also prompt men to consume convenient, unhealthy foods, such as fast food. In a way, for older adults what motivates the selection of food includes the sensory perceptions of taste rather than convenience, monetary considerations and physical well-being (BETTS, 1985; FALK et al.; 1996; KRONDL et al.,1982). That can also be one of the reasons why 
cooking shows are trending, gastronomy has become an increasingly popular spectator sport (POLLAN, 2009).

Regarding the information collected, two personas (Figure 2) were created: Amanda - a 25-year-old that left her hometown to study law and is an intern at a big company, she prepares her meals at night, because there is no other time for cooking, and misses having dinner with her big family. - And Daniel - the 35-year-old IT (Information Technology) technician who likes to order food and stay up late, watching cooking reality shows because the food looks nice but doesn't know much more than how to fry an egg.

Figure 2 - Personas - Daniel and Amanda.
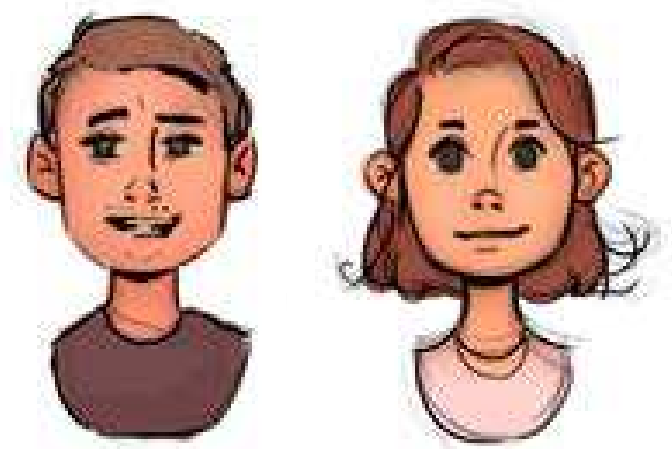

Source: Eatable - Authors and Non-authors group, 2017

\section{ViP Deconstruct (Research + Know the User)}

It is the Vision in Product that aims to design a product or service for the future. This tool deconstructs a product/service to understand it in a context, creating the possibility to design a new project or concept (MEDIALAB AMSTERDAM, 2017).

After organizing, thinking about reasons and identifying the product/ service that needed to be deconstructed to address the needs of the personas, a selection was made - FOOD RECIPES.

"Recipe is a set of instructions telling you how to prepare and cook food, including a list of what food is needed for it" (CAMBRIDGE DICTIONARY, 2017) or pieces of communication composed and transmitted for the purpose of teaching someone how to prepare certain type of food. According to Milica et al. (2017) they can be passed on orally and in wri- 
ting, but the peculiarities of the communicative channel determine the presence or the absence of certain structural components in the preparation of recipes. Enough to understand that, in the process of oral transmission, the message is supported by both paralinguistic (accent, tempo, intonation) and non-linguistic elements (body language) which disappear when the recipes are written down; where writing has, its strategic benefits concerning the accuracy, stability and durability of information.

Although, it is natural to assume that one person, with no experience in cooking, cannot fully comprehend or interpret a recipe correctly, what can be due to a lack of skills and practice, one can always improve these skills with guidance, lessons and orientation. Short $(2003 ; 2006)$ describes the types of skills involved in today's cooking as mechanical, technical, perceptual, conceptual, organizational, and academic. In other words, these skills should not be reduced to the ability to do tasks such as baking, broiling, poaching, and stir-frying, which is an oversimplification of activities involved in planning, organizing, and preparing a meal.

With such oversimplification of cooking and how cooking has evolved over the past century, from the use of almost entirely raw ingredients to today's thousands of available food products that often require little or no transformation before consumption, domestic cooking practices became complex to comprehend in a food system with an increasing prevalence of highly processed foods (SHAPIRO, 2004).

By deconstructing recipes and tackling how to improve a person skill on making food as a way to eat healthier meals, the product concept started with the guidelines: It should adapt to every kitchen; it must be interactive; cleanable, due to the kitchen environment; it needs to teach or guide the user through a recipe and allow voice commands, if hands are busy.

\section{Empathy Map (Create + Frame Insights)}

This is a tool to help a design team to empathize with the people they are designing for (MEDIALAB AMSTERDAM, 2017). In this project, the empathy map (figure 3 ) was created for a faster visualization of the personas needs and behaviors based on the research data, showing the means to better understand and prevent for possible problems regarding what the user would feel like, their sensory experience, the pains and gains when entering in contact with the concept and how using it will affect them. 
Figure 3 - Empathy Map

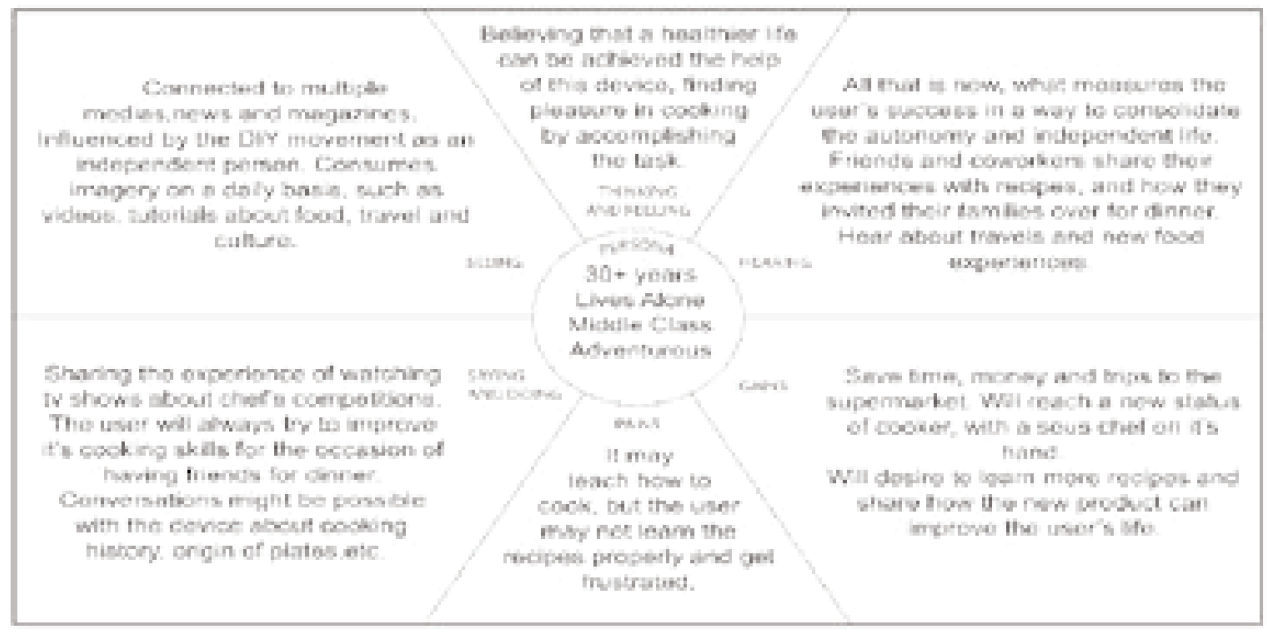

Source: Eatable - Authors and Non-authors group, 2017.

\section{ViP Design (Create + Ideation \& Concepts)}

Vision in Product Design is the tool that aims to design towards a desired future in whicth a product fits (MEDIALAB AMSTERDAM, 2017). With the ViP Deconstruct and the Empathy Map as research background, the need for an analysis of related works presented itself, in order to create something completely new for a future context. The selection of works presented below were based on a level of similarity regarding the interaction intended for the concept project. As a way to visualize each of the works analyzed, a brief description and a correspondent image will be positioned bellow.

Cooking Navi: by optimizing the cooking procedure considering some restrictions: Duration of cooking, accuracy of cooking, and learning effect, providing appropriate instructions to users at the right timing (TANAKA et al., 2005).

Figure 4 - Cooking Navi: Assistant for daily cooking in the kitchen.

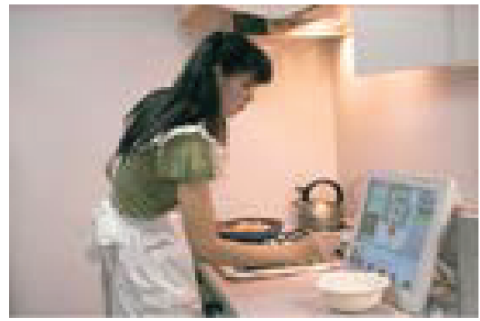

Source: TANAKA et al., 2005 


\section{LOGO}

SmartKitchen: an interdisciplinary research project focusing on interactive display deployment in the kitchen around the cooking area (ENGELN et al., 2016).

Figure 5 - SmartKitchen - Mock-up of the envisioned media enhanced cooking environment.

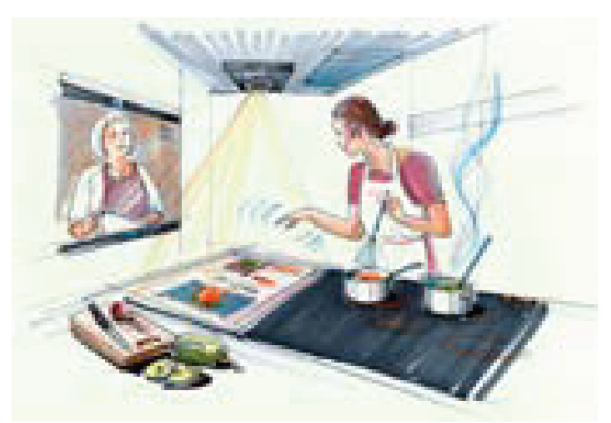

Source: ENGELN et al., 2016.

Panavi: a system that consists of three parts; the special kitchen utensil (frying-pan) with embedded sensors, the display system connecting the computer with the touch monitor, the projection system and the software system (URIU et al., 2012).

Figure 6 - Panavi: System Architecture

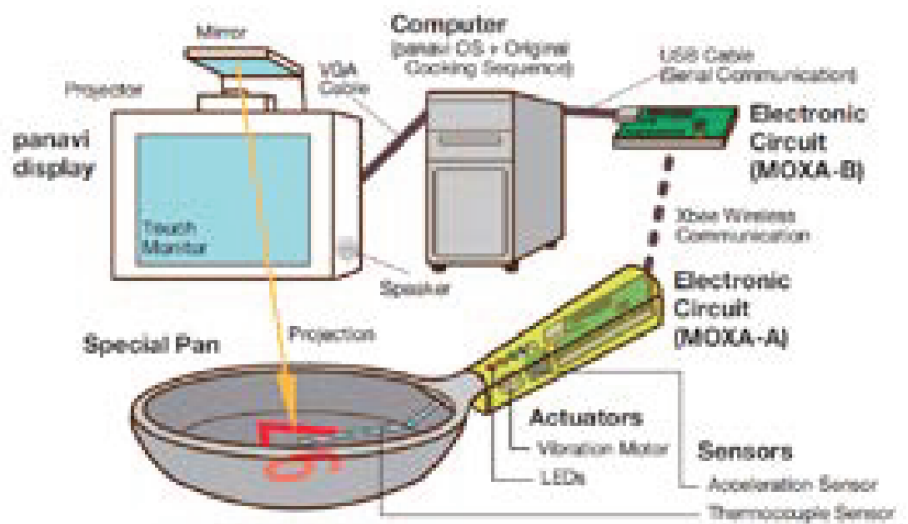

Source: URIU et al., 2012.C

CounterActive: an interactive kitchen cookbook that teaches people to cook. It provides instructions and pictures showing how to cook various recipes, but has the capability to provide movies, music and help on demand too (LEE et al., 2001). 
Figure 7 - Diagram of the CounterActive System.

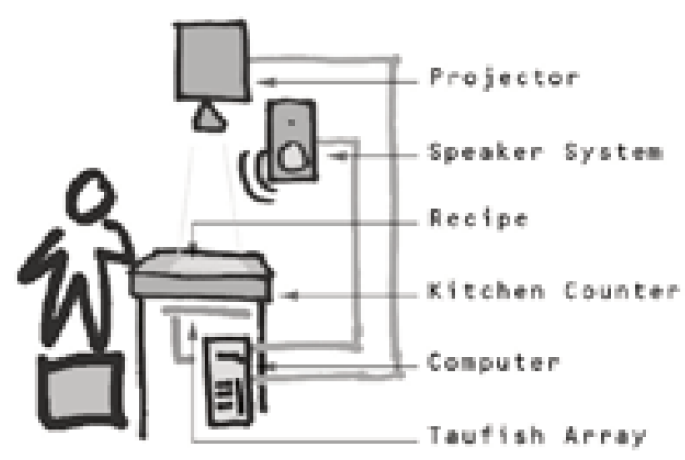

Source: LEE et al., 2001.

Shadow Cooking: Is step-by-step guide information projected on a kitchen counter. It consists of a depth camera and a projector, which are installed above the kitchen counter. The system also integrates a digital kitchen scale with the recipe such that the user is automatically prompted with the required weight based on the ingredient currently being measured (SATO et al.,2014).

Figure 8 - Shadow Cooking: Situated Guidance for Fluid Cooking Experience.

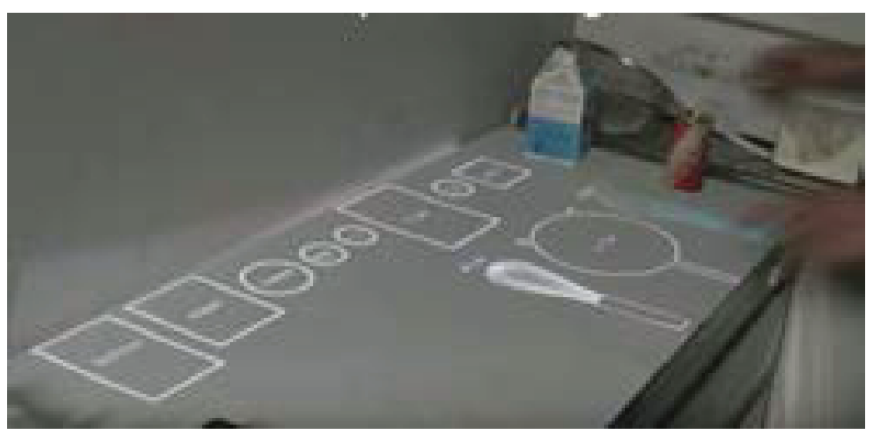

Source: SATO et al., 2014.

\section{Eatable Concept}

The visual representation of the concept would be very similar to a glass cutting board along with an induction space for a pan to cook (figure 9). Regarding the technology necessary to implement this concept, in a context future, the product would have to be integrated and smart enough to analyze all sorts of data to fully function. What was highly considered was the use of artificial intelligence(Al), on the premises that this concept will use intelligent user interface(IUI) along with human-computer 
interaction $(\mathrm{HCl})$. These combined tools can provide for a multimodal interaction, which according to Sonntag (2012) can be advanced analytical methods for understanding multiple sensory input modalities or by the emergence of a complex multimodal behavior which, if performed by a human, would be deemed intelligent.

Figure 9 - Concept Idea.

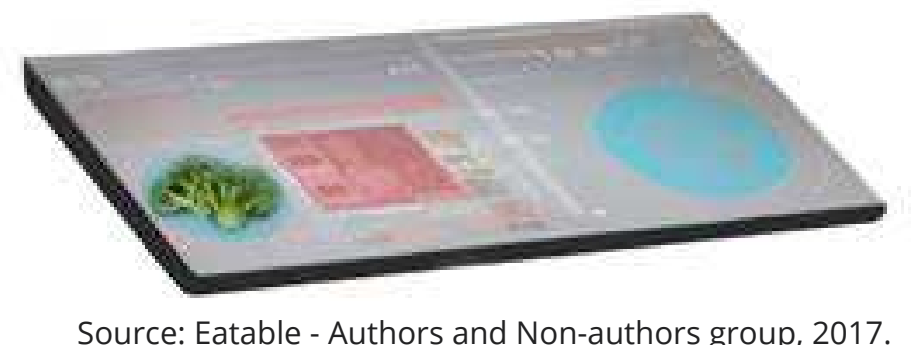

Considering the performance of such product, it was assumed a presence of multiple sensors integrated to provide the user all information needed to perform the task of cooking. So in essence, the base would contain: a scaling and pressure system, a heat signature reader, image scanning processor, smart glass for viewing and showing data, induction stove, cut proof screen and sound speakers. The specific areas of its functionality can be seen in figure 10, created upon a frame of the moving visual representation of the concept found in Meiborg et al. (2017).

Figure 10 - Eatable Functionality Areas.

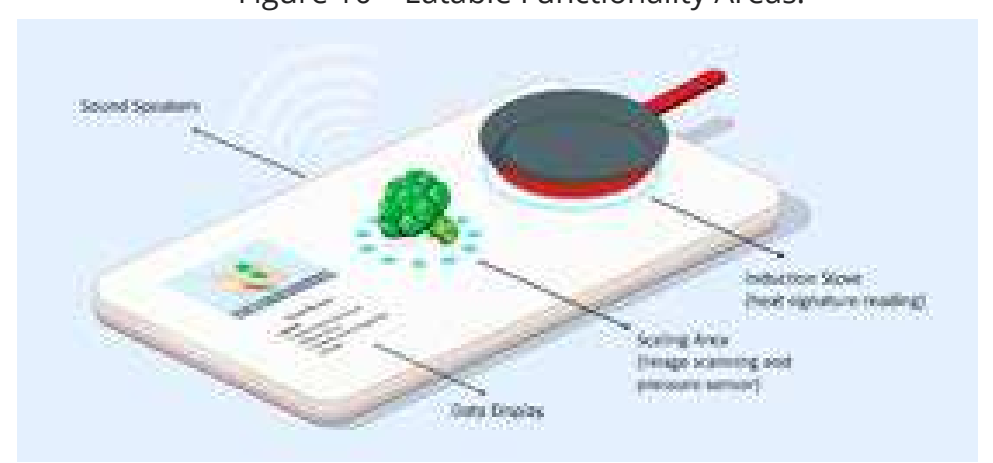

Source: Eatable - Authors, 2017.

The interaction was designed to happen in this order: the user could start by navigating on the surface to search recipes they want to prepare or they could place any ingredient on the top of the surface to be scanned and interpreted by the sensors beneath the smart glass, showing the 
proportion and amounts needed in the recipe. In this way, by showing the exact amount of the ingredient, the user can do a selection of the size of the portion, and a "how to cook" or "recipe" would appear in the screen to start and teach the next steps.

Figure 11 - Eatable - Concept in a situation of use.

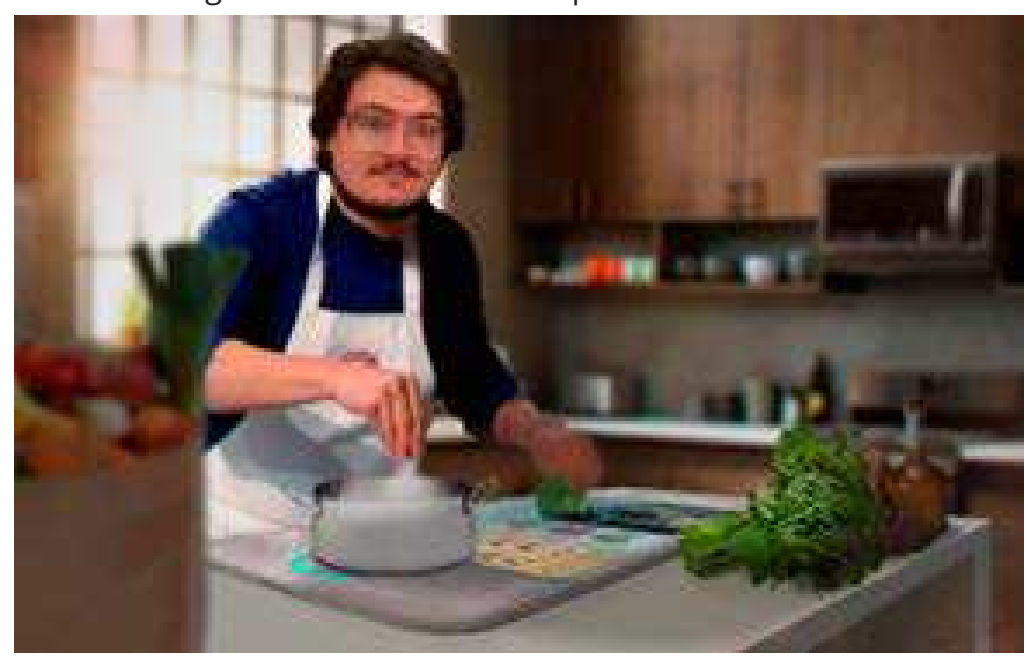

Source: Eatable - Authors and Non-authors group, 2017.

\section{Eatable Concept Validation}

For the validation of this project a tool developed by Ribeiro et al. (2016) was used. The Emoji Tool, an evaluation tool that consists on a 5-points Likert scale for each of the 14 different emotions (positive emotions: desire, fascination, hope, admiration, pride, joy and satisfaction; and negative emotions: contempt, dissatisfaction, boredom, fear, sadness, shame and disgust). The Likert Scale ranges from 1 to 5, where 1 represents "I feel a little emotion" and 5 "I fell a lot of emotion" (LIKERT, 1932).

With this tool, there is no correct and incorrect answer for each individual response, but a comparison between the positive and negative emotion, in other words, their amplitude. For example, if the satisfaction emotion gets a 5 rating and the dissatisfaction emotion gets a 4 it is barely relevant if compared to a satisfaction 5 and a 1 dissatisfaction.

This validation was performed inside the campus (UTFPR), were a brief presentation of the personas (figure 2) and the concept idea (figure 9) were shown on a screen along with a detailed script of the interaction presented by the Authors and Non-authors to two separate groups, students of the Conceptual Design discipline and Design students from dif- 


\section{LOGO}

ferent disciplines on campus. The results gathered from the participants are displayed in Chart 1 as the average answers of 15 students from each of the groups.

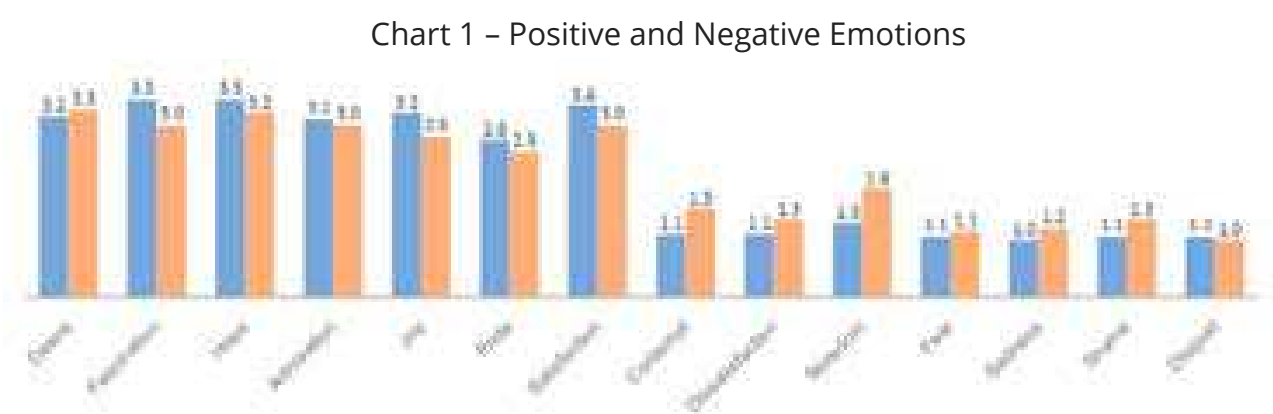

Source: Eatable - Authors and Non-authors group (2017).

Considering that most of the positive answers were above the middle point (2.5) and the negative were under the middle point, by interpretation, the Chart 1 shows that most participants from both groups had a positive response to the concept. Although, students from inside the classroom showed a more critical response, due to the previous knowledge of the concept proposal presented in the discipline prior to the concept analysis.

\section{Conclusion}

The importance of the toolkit as a research and design methodology to create the Eatable concept proved to be an easy step-by-step guidance, that brought the discussion about the dissolution of communality with the beginning of the eating solo trend. Such trend increased many issues in society, regarding dietary behaviors, that can be minimized with the use of a concept such as Eatable, by guiding and teaching the knowledge behind food and its preparation. Also, helping users to pursue a healthier diet diminishing the tendency to consume ready-made or fast-food that leads to malnutrition by cooking at home, which according to Shapiro (2004) proved to be more than a solution, it is now a survival skill, due to the long process of faithfully turning over the decisions about what people eat to the food industry in the name of habit or convenience, what steered society to staggering rates of obesity and diabetes.

On the technological viewpoint, considering the rapid pace of recent technological advances, it's possible to assume the viability of such con- 
cept in an upcoming future, despite the inexistent or very premature stages of the technology required for its production. Also, when placing a comparison with everything that is being intellectually produced relating to kitchen assistants or cooking apparatus it might suggest that this is the way forward, the future. Building smart solutions for real time multitasks. Products for cooking such as Eatable proved to be well-accepted, considering the participants surveyed in this project and related works.

\section{References}

AQUINO, Matheus M.; MAXIMIANO, Davi B.; SILVA, Natália A. C. Eatable - non-authors group members. Federal Technological University of Paraná, 2017.

BAKER, A. H.; \& WARDLE, J. Sex differences in fruit and vegetable intake in older adults. Appetite, 40(3), 269-275, 2003.

BETTS, N. M. A method to measure perceptions of food among the elderly. Journal of Nutrition for the Elderly, 4(4), 15-21, 1985.

CAMBRIDGE DICTIONARY. Recipe, 2017. Found in http://dictionary.cambridge.org/pt/dicionario/ingles/recipe

CHAMIE, Joseph. The Rise of One-Person Household. Inter Press Service, February 22, 2017 (posted by Global Issues). Found at: http://www.globalissues.org/news/2017/02/22/22900

ENGELN, A.; ZIMMERMANN, G.; SCHEIBLE, J.; FUNK, M.; BURMESTER, M.; PALM, S.; KEBER, T.; SCHAUMANN, U.; SCHULZ, U. SmartKitchen Media Enhanced Cooking Environment. loT'16, Stuttgart - Germany, 2016. ENGLER-STRINGER, Rachel. Food, cooking and health: A literary review. Canadian Journal of Dietetic Practice and Research, 2010.

FALK, L. W.; BISOGNI, C. A.; \& SOBAL, J. Food choice processes of older adults: a qualitative investigation. Journal of Nutrition Education, 28(5), 257-265, 1996.

FISCHLER, Claude. Food Habits, social change and the nature/culture dilemma. Social Science Information, 19. 937-953, 1980.

FISCHLER, Claude. L'homnivore. Le gofit, la cuisine et le corps. Paris, Éditions Odile Jacob, 1990.

FISCHLER, Claude. Commensality, Society and Culture. Social Science Information. 2011.

GERMOV, John. Whetting the appetite: a taste of the sociology of food and nutrition. Health Sociology Review, 7: 35-46,1997.

HERMAN, C. Peter; ROTH, Deborah A.; POLIVY, Janet. Effects of the pre- 
sence of others on food intake: a normative interpretation. Psychological bulletin, 129: 873-886, 2003.

HUGHES, G.; BENNETT, K. M.; \& HETHERINGTON, M. M. Old and alone: barriers to healthy eating in older men living on their own. Appetite, 43(3), 269-276, 2004.

KLINENBERG, Eric. I want to be alone: the rise and rise of solo living. The Guardian, 2012. Found in https://www.theguardian.com/lifeandstyle/2012/mar/30/the-rise-of-solo-living

KRONDL, M.; LAU, D.; YURKIW, M. A.; COLEMAN, P. H. Food use and perceived food meanings of the elderly. Journal of the American Dietetic Association, 80(6), 523-529, 1982.

LEE, B.; HURWITZ, R.; JUDD, T.; JU, W. CounterActive: An Interactive Cookbook for the Kitchen Counter. MIT Media Lab, 2001.

LIKERT, R. A Technique for the Measurement of Attitudes. Archives of Psychology, 140, 1-55,1932.

MEDIALAB AMSTERDAM. Design Process and Programme. 2016

MEDIALAB AMSTERDAM. Design Method Toolkit. 2017 Found in http:// medialabamsterdam.com/toolkit/using-the-toolkit/

MEIBORG, E.C.H.; RIBEIRO, R.P. Eatable Concept Functionality. Found at: https://youtu.be/nr6IMz6a4no

MILICA, I.; GUIA, S. Culinary recipes: orality and scripturality (I). Faculty of Letters, Alexandru Ioan Cuza University, Romania, 2017.

OXFORD ENGLISH DICTIONARY. Digitization, 2017. Found in https:// en.oxforddictionaries.com/definition/digitization

PENTEADO, A.C.; RIBEIRO, R.P. Ferramentas para a Avaliação de Design Emocional em Projetos de Design. UTFPR Faz Pesquisa em Design, Curitiba-Brazil, 2016.

PLINER, P.; BELL R. A table for one: the pain and pleasure of eating alone. In: Meiselman HL (ed.) Meals in Science and Practice: Interdisciplinary research and business applications. Cambridge: CRC Press \& Woodhead, 169-89. 2009.

POLLAN, Michael. Out of the kitchen, onto the couch. The New York Times, 2 of August. 2009. Found in: http://www.nytimes.com/2009/08/02/ magazine/02cookingt.html

RICHARDS, Aubrey. Hunger and Work in a Savage Tribe - A functional study of nutrition among the Southern Bantu. London: Routledge. 1932.

SATO, A.; WATANABE, K.; REKIMOTO, J. Shadow Cooking: Situated Guidance for a Fluid Cooking Experience. UAHCI/HCII 2014, Part III, LNCS 8515, pp. 558566, 2014. Also found in: https://www.youtube.com/watch?v=R-HLuTEncWO 
SHAPIRO, L. Something from the oven. New York: Penguin; 2004.

SHORT, F. Domestic cooking skills-what are they?.J Home Econ Inst Aust.10(3):13-22, 2003.

SHORT, F. Kitchen secrets: the meaning of cooking in everyday life. Oxford: Berg; 2006.

SONNTAG, Daniel. Collaborative Multimodality. German Research Center for Al (DFKI), Springer-Verlag 2012.

TAKEDA, Wakako. Reconsidering Individualisation of Eating: a cross-cultural analysis on determinants of commensality and solo-eating. Australian National University, 2016.

TANAKA, H.; IDE, I.; OKABE, J.; HAMADA, R.; SATOH, S.; SAKAI, S. Cooking Navi: Assistant for Daily Cooking in Kitchen. Singapore, 2005.

TANI, Y.; KONDO, N.; TAKAGI, D.; SAITO M.; HIKICHI, H.; OJIMA, T.; KONDO, $K$. Combined effects of eating alone and living alone on unhealthy dietary behaviors, obesity and underweight in older Japanese adults: Results of the JAGES. Appetite - eating and drinking 95, 1e8, 2015.

URIU, D.; INAMI, M.; NAMAI, M.; OKUDE, N.; KASHIWAGI, R.; TOKUHISA, S. Panavi: Recipe Medium with Sensors-Embedded Pan for Domestic Users to Master Professional Culinary Arts. Graduate School of Media Design, Keio University (KMD) \& Keio-NUS CUTE Center, 2012. 


\section{Rosamelia Parizotto Ribeiro}

Bachelor's degree in Industrial Design from the Pontifical Catholic University of Paraná (1990), Specialization in Marketing - Emphasis in Advertising by the Faculty of Administration and Economics (1993), Graduation in Specialist Teachers' Training by the Federal Technological University of Paraná (1994) in Production Engineering, emphasis on Human-Computer Interaction by the Federal University of Santa Catarina (1997) and PhD in Psychology (Interaction Design) by the University of York, United Kingdom (2007). Professor of the Federal Technological University of Paraná in the courses of Graphic Design, Design and Specialization in the area of Design. Has interests in the areas of Emotional Design, Conceptual Design, Visual Identity, Graphic Production, Human-Computer Interface, Ergonomics and Usability and Graphical Web Interfaces.

\section{Eleny Carolien Hillenia Meiborg}

Bachelor of Design from the Federal Technological University of Paraná (2017), with a Scholarship from the CAPES Science Mobility Program for one year with admission to the New York Institute of Technology, United States of America (2014), Continuing Education in Beginners Jewelry and Intermediate Jewelry by the School of Visual Arts, United States of America (2014). With research interests in the area of Interaction Design, Cybernetics and Artificial Intelligence. 